Check for updates

Cite this: RSC Adv., 2017, 7, 55891

Received 10th November 2017 Accepted 3rd December 2017

DOI: 10.1039/c7ra12318c

rsc.li/rsc-advances

\title{
Use of unprotected amino acids in metal-free tandem radical cyclization reactions: divergent synthesis of 6-alkyl/acyl phenanthridines $\uparrow$
}

\author{
Shi-Chao Lu, (D) ${ }^{a}$ Hong-Shuang Li, (D) *b Ya-Ling Gong, ${ }^{a}$ Xiao-Lei Wang, ${ }^{a}$ Fu-Rong Li, ${ }^{\text {b }}$ \\ Fei Li, ${ }^{\mathrm{b}}$ Gui-Yun Duan ${ }^{\mathrm{b}}$ and Shu Xu (D) *a
}

We reported the first example of the construction of $\mathrm{C}-\mathrm{C}$ bonds using unprotected amino acids as stable alkyl/acyl radical precursors under metal-free conditions. This novel, environmentally friendly, and one-pot procedure was successfully applied to the radical alkylation or acylation/cyclization of isocyanides, which selectively affords 6-alkyl or acyl phenanthridines, depending on the substituent pattern of amino acid side chain groups.

\section{Introduction}

As an important building block, amino acids present the advantages of high stability, abundant natural resources, structural diversity and low cost, which make them ideal synthons for chemical synthesis. ${ }^{1}$ Although numerous methods for the introduction of amino acids into diverse organic structures via peptide coupling have been described, ${ }^{2}$ the application of amino acids in $\mathrm{C}-\mathrm{C}$ bond-forming reactions is far less studied. In this context, synthetic utilization of $\alpha$-aminoalkyl radicals generated by metal- or photo-catalyzed radical decarboxylation of N-protected amino acids has been achieved for the construction of $\mathrm{C}-\mathrm{C}$ bonds (Scheme 1a and b). These reactions involved cross-coupling, ${ }^{3}$ conjugate additions, ${ }^{4}$ and Minisci reactions with electron-deficient heteroarenes. ${ }^{5}$ However, the strategy for the generation of the alkyl radicals from unprotected amino acids was seldom applied to molecular transformations due to their tendency for rapid oxidation of unprotected $\alpha$-aminoalkyl radicals. Very recently, Baxter successfully realized a silver-catalyzed heterocycle $\mathrm{C}-\mathrm{H}$ alkylation reaction using unprotected amino acids as stable radical precursors (Scheme 1c). ${ }^{6}$ This transformation was believed to undergo in situ aldehyde formation, namely Strecker degradation, ${ }^{7}$ followed by a Minisci-type radical decarbonylation/ alkylation process. While radical alkylation reactions via aldehyde decarbonylation are known, ${ }^{8}$ aliphatic aldehydes are

${ }^{a}$ State Key Laboratory of Bioactive Substance and Function of Natural Medicines, Beijing Key Laboratory of Active Substance Discovery and Drugability Evaluation, Institute of Materia Medica, Peking Union Medical College, Chinese Academy of Medical Sciences, No. 1 Xiannongtan Street, Beijing 100050, PR China. E-mail: xushu@imm.ac.cn

${ }^{b}$ School of Pharmaceutical Sciences, Taishan Medical University, 619 Changcheng Road, Taian 271016, PR China. E-mail: lihongshuang8625@163.com

$\dagger$ Electronic supplementary information (ESI) available: General considerations, experimental procedures, spectroscopic data. See DOI: 10.1039/c7ra12318c redox-sensitive liquids and usually require cold storage and special operations. In contrast, the resulting alkyl radicals via the multistep oxidative degradation of amino acids showed better selectivity and reactivity. ${ }^{6}$ However, all of the reactions involving the use of amine acids as radical precursors reported so far require a toxic transition metal catalytic system. In view of this, the development of a green reaction system for the construction of $\mathrm{C}-\mathrm{C}$ bonds using amino acids as stable radical precursors is highly desirable and challenging.

Recently, the radical oxidative addition/cyclization of 2-isocyanobiphenyls with different radical precursors to synthesize functionalized phenanthridines, which are widely found in various natural products and possess a wide range of biological activities, ${ }^{9}$ have been extensively investigated..$^{10}$ Our group has recently also reported a radical cascade decarboxylation/ cyclization of 2-isocyanobiphenyls with carboxylic acids to afford 6-alkyl/aryl phenanthridines. ${ }^{10 d}$ Although these methods have their own specific applications, they still suffer from one or more limitations, such as a limited reaction scope, harsh

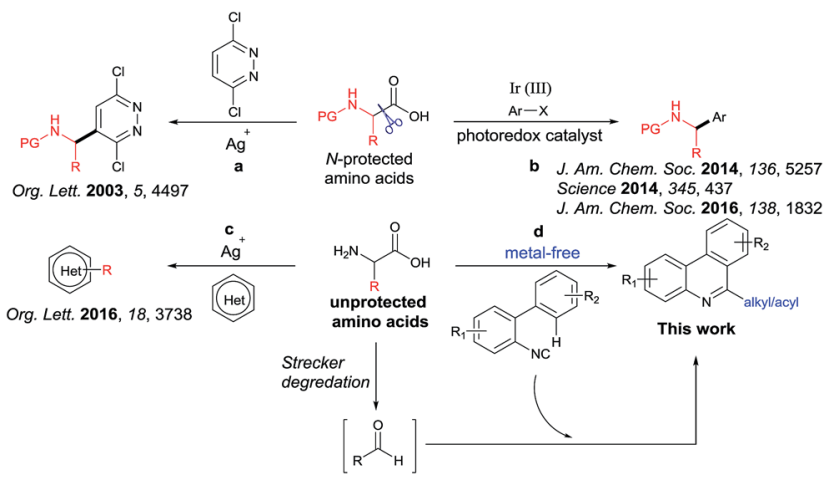

Scheme 1 Amino acids as a source of alkyl radicals for $\mathrm{C}-\mathrm{C}$ bondforming reactions. 
reaction conditions, long reaction times, and the use of transition-metal catalysts. Therefore, it is still necessary to develop more radical precursors for practical, general, and environmentally benign methods to realize the addition/ cyclization of 2-isocyanobiphenyls. To the best of our knowledge, amino acids have not been used as a source of radicals for construction of heterocycles. Herein, we develop a novel strategy that utilizes unprotected amino acids as inexpensive alkyl/acyl radical precursors for the addition/cyclization of 2isocyanobiphenyls under metal-free conditions in aqueous solution, which provides a simple and general protocol for the divergent synthesis of 6-alkyl/acyl phenanthridines (Scheme 1d).

\section{Results and discussion}

In our initial studies, we selected 2-isocyano-1,1'-biphenyl (1a) and L-tert-leucine (2a) as model substrates to investigate the reaction conditions. Inspired by our previous research on decarboxylative cross-coupling reactions, the model reaction was carried out in $\mathrm{CH}_{3} \mathrm{CN} / \mathrm{H}_{2} \mathrm{O}(1: 1)$ at $80{ }^{\circ} \mathrm{C}$ in the presence of 3.0 equiv. of $\mathrm{K}_{2} \mathrm{~S}_{2} \mathrm{O}_{8}$ and 1.5 equiv. of $\mathrm{K}_{2} \mathrm{CO}_{3}$. To our delight, the desired product 3a was obtained in a $36 \%$ yield. In view of the fact that the addition of $20 \mathrm{~mol} \%$ of $\mathrm{AgNO}_{3}$ cannot improve the yield (Table 1, entry 1), we decided to explore the metal-free oxidative radical cyclization for the construction of 6-alkyl phenanthridines. A survey of the reaction parameters, such as the oxidants, bases, solvents and temperature, were conducted. Increasing the temperature to $100{ }^{\circ} \mathrm{C}$ gave good conversion to the expected product (Table 1, entry 2). Further investigation on the bases, such as $\mathrm{Na}_{2} \mathrm{CO}_{3}, \mathrm{~K}_{3} \mathrm{PO}_{4}, \mathrm{Cs}_{2} \mathrm{CO}_{3}$, and $\mathrm{NaOAc}$, revealed that $\mathrm{K}_{2} \mathrm{CO}_{3}$ was the best choice (Table 1, entries 3-6). Subsequently, we attempted to examine the effect of different solvent systems on the model reaction. Among the solvents screened, water-miscible solvents (Table 1, entries 7-10) as well as water (Table 1, entry 11) were not effective for this transformation. In addition, the reaction was also not carried out in biphasic mixtures (DCE/ $\mathrm{H}_{2} \mathrm{O}$ ) (Table 1 , entry 12). It was observed that increasing the ratio of $\mathrm{CH}_{3} \mathrm{CN}$ to $\mathrm{H}_{2} \mathrm{O}$ had a positive effect on the yield of $3 \mathbf{a}$ (Table 1, entries 13 and 14). When the ratio was $5: 1$, the reaction can be achieved in a $78 \%$ yield. However, $98 \%$ of the reactant 1a was recovered while using $\mathrm{CH}_{3} \mathrm{CN}$ as the sole solvent (Table 1, entry 15). Similarly, other anhydrous organic solvents such as DMF, DMSO, or THF were not effective for this conversion. Further investigation showed that both $\mathrm{Na}_{2} \mathrm{~S}_{2} \mathrm{O}_{8}$ and $\left(\mathrm{NH}_{4}\right)_{2} \mathrm{~S}_{2} \mathrm{O}_{8}$ negatively affected the reaction (Table 1, entries 16 and 17). Meanwhile, the decreasing the amount of $\mathrm{K}_{2} \mathrm{~S}_{2} \mathrm{O}_{8}$ led to a low yield (Table 1, entry 18). The control experiment indicated that $\mathrm{K}_{2} \mathrm{~S}_{2} \mathrm{O}_{8}$ was necessary for the transformation (Table 1, entry 19). The optimal conditions were finally determined to be

Table 1 Optimization of the reaction conditions ${ }^{a}$

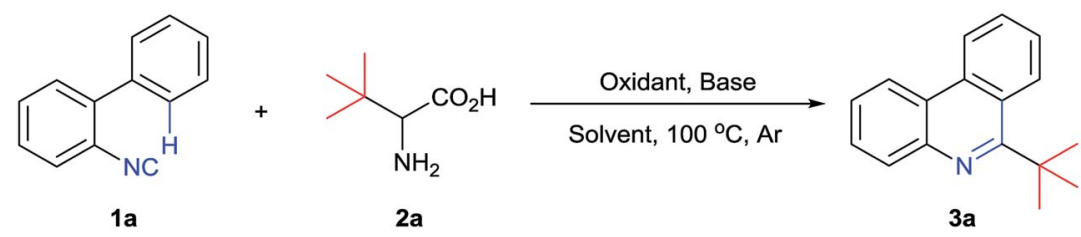

\begin{tabular}{|c|c|c|c|c|}
\hline Entry & Oxidant (equiv.) & Base (equiv.) & Solvent (v/v) & Yield $^{b}$ \\
\hline $1^{c}$ & $\mathrm{~K}_{2} \mathrm{~S}_{2} \mathrm{O}_{8}(3.0)$ & $\mathrm{K}_{2} \mathrm{CO}_{3}(1.5)$ & $\mathrm{CH}_{3} \mathrm{CN} / \mathrm{H}_{2} \mathrm{O}(1: 1)$ & $36(38)^{d}$ \\
\hline 2 & $\mathrm{~K}_{2} \mathrm{~S}_{2} \mathrm{O}_{8}(4.0)$ & $\mathrm{K}_{2} \mathrm{CO}_{3}(2.0)$ & $\mathrm{CH}_{3} \mathrm{CN} / \mathrm{H}_{2} \mathrm{O}(1: 1)$ & $62(54)^{e}(60)^{f}$ \\
\hline 4 & $\mathrm{~K}_{2} \mathrm{~S}_{2} \mathrm{O}_{8}(4.0)$ & $\mathrm{K}_{3} \mathrm{PO}_{4}(2.0)$ & $\mathrm{CH}_{3} \mathrm{CN} / \mathrm{H}_{2} \mathrm{O}(1: 1)$ & 42 \\
\hline 5 & $\mathrm{~K}_{2} \mathrm{~S}_{2} \mathrm{O}_{8}(4.0)$ & $\mathrm{Cs}_{2} \mathrm{CO}_{3}(2.0)$ & $\mathrm{CH}_{3} \mathrm{CN} / \mathrm{H}_{2} \mathrm{O}(1: 1)$ & 46 \\
\hline 6 & $\mathrm{~K}_{2} \mathrm{~S}_{2} \mathrm{O}_{8}(4.0)$ & NaOAc (2.0) & $\mathrm{CH}_{3} \mathrm{CN} / \mathrm{H}_{2} \mathrm{O}(1: 1)$ & 27 \\
\hline 9 & $\mathrm{~K}_{2} \mathrm{~S}_{2} \mathrm{O}_{8}(4.0)$ & $\mathrm{K}_{2} \mathrm{CO}_{3}(2.0)$ & $\mathrm{DMSO} / \mathrm{H}_{2} \mathrm{O}(1: 1)$ & 12 \\
\hline 10 & $\mathrm{~K}_{2} \mathrm{~S}_{2} \mathrm{O}_{8}(4.0)$ & $\mathrm{K}_{2} \mathrm{CO}_{3}(2.0)$ & Acetone $/ \mathrm{H}_{2} \mathrm{O}(1: 1)$ & 0 \\
\hline 11 & $\mathrm{~K}_{2} \mathrm{~S}_{2} \mathrm{O}_{8}(4.0)$ & $\mathrm{K}_{2} \mathrm{CO}_{3}(2.0)$ & $\mathrm{H}_{2} \mathrm{O}$ & 0 \\
\hline 12 & $\mathrm{~K}_{2} \mathrm{~S}_{2} \mathrm{O}_{8}(4.0)$ & $\mathrm{K}_{2} \mathrm{CO}_{3}(2.0)$ & $\mathrm{DCE} / \mathrm{H}_{2} \mathrm{O}(1: 1)$ & 0 \\
\hline 13 & $\mathrm{~K}_{2} \mathrm{~S}_{2} \mathrm{O}_{8}(4.0)$ & $\mathrm{K}_{2} \mathrm{CO}_{3}(2.0)$ & $\mathrm{CH}_{3} \mathrm{CN} / \mathrm{H}_{2} \mathrm{O}(3: 1)$ & 72 \\
\hline 14 & $\mathrm{~K}_{2} \mathrm{~S}_{2} \mathrm{O}_{8}(4.0)$ & $\mathrm{K}_{2} \mathrm{CO}_{3}(2.0)$ & $\mathrm{CH}_{3} \mathrm{CN} / \mathrm{H}_{2} \mathrm{O}(5: 1)$ & 78 \\
\hline 19 & - & $\mathrm{K}_{2} \mathrm{CO}_{3}(2.0)$ & $\mathrm{CH}_{3} \mathrm{CN} / \mathrm{H}_{2} \mathrm{O}(5: 1)$ & 0 \\
\hline
\end{tabular}

${ }^{a}$ Reaction conditions: 1a $(0.2 \mathrm{mmol}), 2 \mathrm{a}(0.4 \mathrm{mmol}), \mathrm{K}_{2} \mathrm{~S}_{2} \mathrm{O}_{8}(0.8 \mathrm{mmol}), \mathrm{K}_{2} \mathrm{CO}_{3}(0.4 \mathrm{mmol})$, in $6.0 \mathrm{~mL}$ of solvent at $100{ }^{\circ} \mathrm{C}$ for $60 \mathrm{~min}$ under $\mathrm{Ar}$.

${ }^{b}$ Isolated yield. ${ }^{c}$ At $80{ }^{\circ} \mathrm{C}^{d} 20 \mathrm{~mol} \%$ of $\mathrm{AgNO}_{3}$ was used as a catalyst. ${ }^{e}$ At $90{ }^{\circ} \mathrm{C} .{ }^{f}$ At $110{ }^{\circ} \mathrm{C}$. 
Table 2 Scope of the oxidative cyclization of isocyanobiphenyls 1 and amino acids $2^{a, b}$

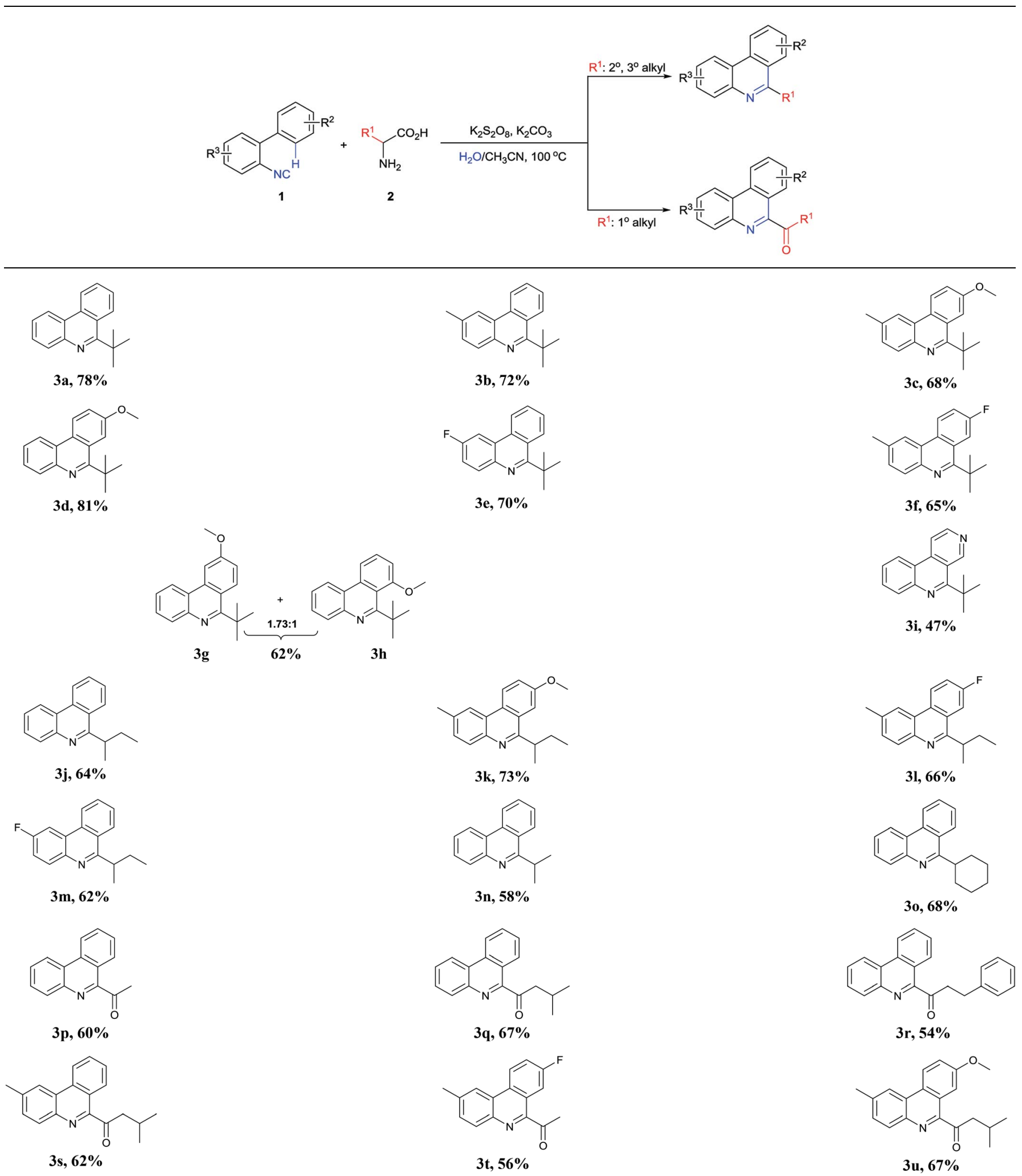




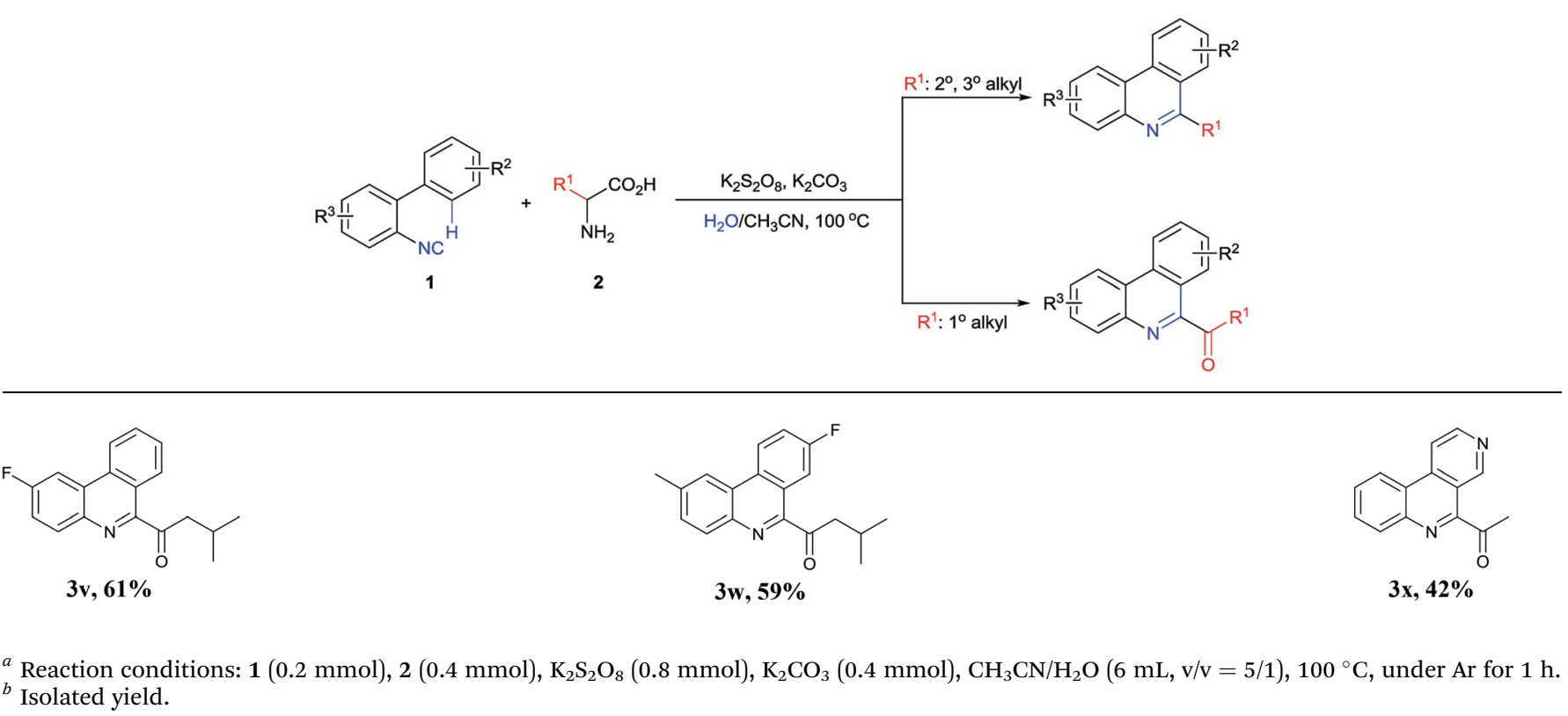

2.0 equiv. of amino acid, 2.0 equiv. of $\mathrm{K}_{2} \mathrm{CO}_{3}$ and 4.0 equiv. of $\mathrm{K}_{2} \mathrm{~S}_{2} \mathrm{O}_{8}$ in $\mathrm{CH}_{3} \mathrm{CN} / \mathrm{H}_{2} \mathrm{O}(\mathrm{v} / \mathrm{v}=5 / 1)$ under $\mathrm{Ar}$ at $100{ }^{\circ} \mathrm{C}$ for $1 \mathrm{~h}$ (Table 1, entry 14).

With the optimized conditions in hand, the scope and limitations of this tandem reaction were then investigated (Table 2). A variety of 2-isocyanobiphenyls containing an electron-withdrawing or electron-donating substituent were reacted with L-tert-leucine $\mathbf{2 a}$ efficiently to afford the corresponding 6-alkyl phenanthridines in moderate to good yields (3a-h). Among them, the cyclization of the meta-substituted substrate preferably took place at the less sterically hindered position ( $\mathbf{3 g}$ and $\mathbf{3 h}$ ). In addition, heterocyclic 2-isocyanobiphenyl was also favored in this system and afforded the corresponding product in a $42 \%$ yield ( $3 \mathbf{i})$. On the other hand, the oxidative cyclization of other unprotected amino acids bearing secondary alkyl substituents (such as valine, isoleucine, and cyclohexylglycine) performed well with a series of 2-isocyanobiphenyls $(\mathbf{3} \mathbf{j}-\mathbf{o})$. It should be noted that this process was

a)

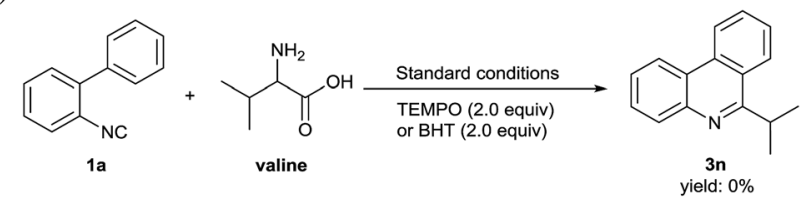

(b)

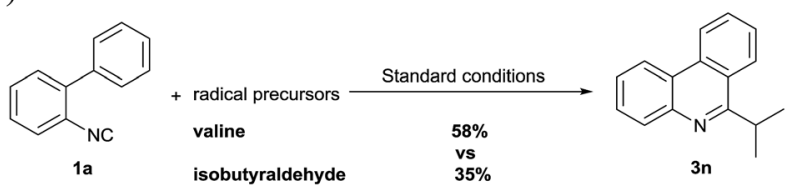

Scheme 2 Control experiments for preliminary mechanism study. limited to simple alkyl-bearing amino acids, while other amino acids with polar side chains, such as asparagine, glutamine, and lysine, failed to afford the corresponding products under the optimized conditions.

Encouraged by the above results, we then investigated the reactivity of amino acids bearing primary side chains (such as alanine, leucine, and homophenyl alanine) toward 2-isocyanobiphenyls. Interestingly, the green system afforded 6-acyl phenanthridines as main products instead of 6-alkyl phenanthridines with moderate to good yields $(\mathbf{3 p}-\mathbf{x})$. These results could be attributed to the stability of the alkyl radical species by
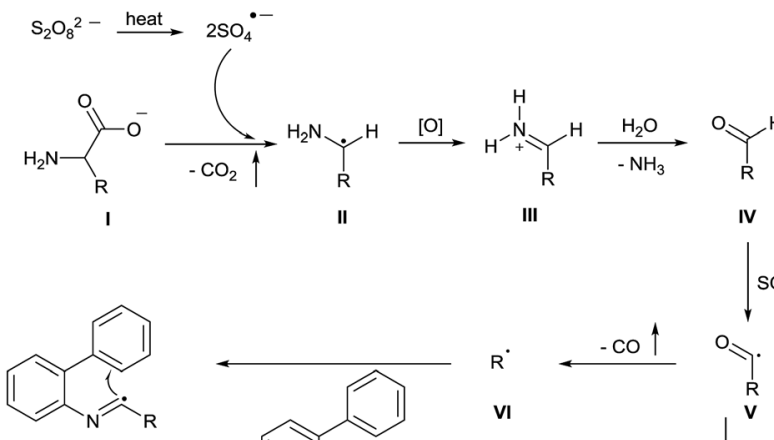<smiles>[R]c1nc2ccccc2c2ccccc12</smiles><smiles>CC(C)(C)[C@H](O)CC(=O)O</smiles><smiles>[R]c1nc2ccccc2c2ccccc12</smiles>

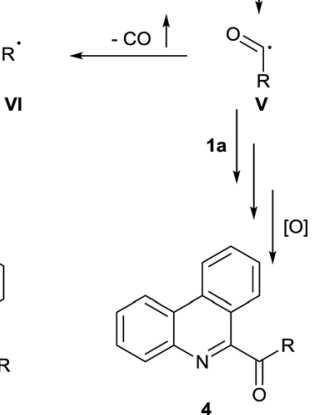

Scheme 3 Postulated reaction pathway. 
decarbonylation of the corresponding acyl radicals. ${ }^{8 g}$ Although some groups have reported their efforts for the synthesis of 6acyl phenanthridines through the reactions of 2-isocyanobiphenyls with corresponding radical precursors including aromatic aldehydes, ${ }^{\mathbf{1 1}}$ potassium oxophenylacetate, ${ }^{\mathbf{1 2}}$ and benzylic alcohols ${ }^{\mathbf{1 3}}$ under iron- or silver-catalyzed radical conditions, the construction of 6-aliphatic acyl phenanthridines remains elusive. In view of this, this strategy afforded a novel, environmentally friendly and complementary approach to produce 6-acyl phenanthridines.

To gather some insights into the mechanism of this reaction, (2,2,6,6-tetramethylpiperdin-1-yl)oxyl (TEMPO, 2.0 equiv.) and 2,6-di-tert-butyl-p-cresol (BHT) as radical scavengers were exposed separately to the standard reaction condition (Scheme 2a). As a consequence, the reaction was completely inhibited, which could indicate that this transformation involves radical intermediates. Then, we chose isobutyraldehyde as a radical precursor to test the radical mechanism (Scheme 2b). The results showed the expected $3 n$ could be obtained in a $35 \%$ yield under the same reaction conditions. By contrast, the multistep degradation of amino acids to generate alkyl radicals offer better reactivity.

On the basis of this observation and the literature evidence, ${ }^{6,10}$ a proposed mechanism is shown in Scheme 3. First, the single-electron oxidative decarboxylation of amino acid anion $\mathbf{I}$ affords a radical $\mathbf{I I}$ in the presence of sulfate anion radicals generated through homolytic cleavage of $\mathrm{K}_{2} \mathrm{~S}_{2} \mathrm{O}_{8}$. Second, II is rapidly oxidized to the corresponding iminium species III and is converted to aldehyde IV in the presence of water. A sulfate anion radical abstracts the aldehyde hydrogen atom to provide the acyl radical $\mathbf{V}$, which undergoes radical decarbonylation to yield the alkyl radical VI. Subsequently, the radical VI adds to the isocyanide 1a to provide the imidoyl radical VII, which undergoes an intramolecular radical cyclization to form the intermediate VIII. Finally, the intermediate VIII is then further oxidized to form the corresponding carbocation, which can be converted to the desired product 3 by losing a proton. In the case of $1^{\circ}$ substituted amino acids, acyl radical $\mathbf{V}$ may be trapped by the isocyanide $\mathbf{1 a}$ to form the acylated product $\mathbf{4}$ in a similar manner.

\section{Experimental section}

\section{General procedure for synthesis of 6-alkyl/acyl phenanthridines}

A $25 \mathrm{~mL}$ oven-dried sealed tube was charged with 2-isocyanobiphenyls (1, $0.20 \mathrm{mmol}, 1.0$ equiv.), amine acids (2, $0.40 \mathrm{mmol}, 2.0$ equiv.), $\mathrm{K}_{2} \mathrm{CO}_{3}$ (55 mg, $0.40 \mathrm{mmol}, 2.0$ equiv.) and $\mathrm{K}_{2} \mathrm{~S}_{2} \mathrm{O}_{8}$ (216 mg, $0.80 \mathrm{mmol}$, 4.0 equiv.) in $\mathrm{CH}_{3} \mathrm{CN} / \mathrm{H}_{2} \mathrm{O}(6.0$ $\mathrm{mL}, \mathrm{v} / \mathrm{v}=5: 1)$. The tube was sealed and heated at $100{ }^{\circ} \mathrm{C}$ for $1 \mathrm{~h}$ under an $\mathrm{Ar}$ atmosphere. After completion of the reaction, the reaction mixture was added water $(5 \mathrm{~mL})$, and then extracted with dichloromethane $(3 \times 5 \mathrm{~mL})$. The combined organic layers were dried over anhydrous $\mathrm{Na}_{2} \mathrm{SO}_{4}$ and evaporated under reduced pressure. The residue was purified by flash column chromatography on silica gel (eluent: petroleum ether/ethyl acetate $=100: 1$ ) to afford 3 .

\section{Conclusions}

In conclusion, we have demonstrated a novel protocol utilizing unprotected amino acids as stable radical sources under metalfree conditions. The method is able to efficiently functionalize 2-isocyanobiphenyls by virtue of the corresponding amino acids, which presents the major advantages of environmentally benign character, a broad substrate scope, and readily available starting materials. Further studies of the reaction mechanism and the extension of the substrate scope are currently underway in our laboratory.

\section{Conflicts of interest}

There are no conflicts to declare.

\section{Acknowledgements}

The research is financially supported by the National Natural Science Foundation of China (21602256, 21502234 and 21672262), the Beijing Natural Science Foundation (2164074), the CAMS Innovation Fund for Medical Sciences (CIFMS, 2016I2M-3-009 and 2017-I2M-2-004), the Research Funds from State Key Laboratory of Bioactive Substance and Function of Natural Medicines (GTZB201404), the Fundamental Research Funds for CAMS/PUMC (2016RC350004), the Natural Science Foundation of Shandong Province (ZR2015BL006, ZR2013HM036) and the Project of Shandong Province Higher Educational Science and Technology Program (J13LM01).

\section{Notes and references}

1 J. M. Humphrey and A. R. Chamberlin, Chem. Rev., 1997, 97, 2243.

2 For a recent review on peptide couplings, see: A. El-Faham and F. Albericio, Chem. Rev., 2011, 111, 6557.

3 (a) Z. Zuo, H. Cong, W. Li, J. Choi, G. C. Fu and D. W. C. MacMillan, J. Am. Chem. Soc., 2016, 138, 1832; (b) Z. Zuo, D. T. Ahneman, L. Chu, J. A. Terrett, A. G. Doyle and D. W. C. MacMillan, Science, 2014, 345, 437; (c) Z. Zuo and D. W. C. MacMillan, J. Am. Chem. Soc., 2014, 136, 5257.

4 (a) S. J. McCarver, J. X. Qiao, J. Carpenter, R. M. Borzilleri, M. A. Poss, M. D. Eastgate, M. Miller and D. W. C. MacMillan, Angew. Chem., Int. Ed., 2017, 56, 728; (b) A. Noble and D. W. C. MacMillan, J. Am. Chem. Soc., 2014, 136, 11602.

5 (a) D. G. M. Shore, K. A. Wasik, J. P. Lyssikatos and A. A. Estrada, Tetrahedron Lett., 2015, 56, 4063; (b) C. J. Cowden, Org. Lett., 2003, 5, 4497.

6 D. N. Mai and R. D. Baxter, Org. Lett., 2016, 18, 3738.

7 (a) O. Nashalian and V. A. Yaylayan, J. Agric. Food Chem., 2014, 62, 8518; (b) G. P. Rizzi, Food Rev. Int., 2008, 24, 416; (c) Y. Zelechonok and R. B. Silverman, J. Org. Chem., 1992, 57, 5787; (d) A. Schonberg and R. Moubacher, Chem. Rev., 1952, 50, 261.

8 For radical-based alkylations from aldehydes, see: $(a)$ C. Pan, Y. Chen, S. Song, L. Li and J. Yu, J. Org. Chem., 2016, 81, 
12065; (b) L. Yang, W. Lu, W. Zhou and F. Zhang, Green Chem., 2016, 18, 2941; (c) S. Paul and J. Guin, Chem.-Eur. J., 2015, 21, 17618; (d) R. J. Tang, L. Kang and L. Yang, Adv. Synth. Catal., 2015, 357, 2055. for radical-based acylations from aldehydes, see: (e) J. Y. Chen, M. Wan, J. Hua, Y. Sun, Z. Lv, W. Li and L. Liu, Org. Biomol. Chem., 2015, 13, 11561; (f) Y. Siddaraju, M. Lamani and K. R. Prabhu, J. Org. Chem., 2014, 79, 3856; (g) P. Cheng, Z. Qing, S. Liu, W. Liu, H. Xie and J. Zeng, Tetrahedron Lett., 2014, 55, 6647; (h) K. Matcha and A. P. Antonchick, Angew. Chem., Int. Ed., 2013, 52, 2082; (i) C. Chatgilialoglu, D. Crich, M. Komatsu and I. Ryu, Chem. Rev., 1999, 99, 1991.

9 (a) L. Sripada, J. A. Teske and A. Deiters, Org. Biomol. Chem., 2008, 6, 263; (b) O. B. Abdel-Halim, T. Morikawa, S. Ando, H. Matsuda and M. Yoshikawa, J. Nat. Prod., 2004, 67, 1119; (c) T. Nakanishi, A. Masuda, M. Suwa, Y. Akiyama, N. Hoshino-Abe and M. Suzuki, Bioorg. Med. Chem. Lett., 2000, 10, 2321; (d) T. Ishikawa, Med. Res. Rev., 2001, 21, 61; (e) S. Simeon, J. L. Rios and A. Villar, Pharmazie, 1989, 44, 593; (f) S. D. Phillips and R. N. J. Castle, Heterocycl. Chem., 1981, 18, 223.

10 For some selected recent examples of preparation of phenanthridines, see: (a) W. Song, P. Yan, D. Shen, Z. Chen, X. Zeng and G. Zhong, J. Org. Chem., 2017, 82, 4444; (b) S. Feng, T. Li, C. Du, P. Chen, D. Song, J. Li, X. Xie and X. She, Chem. Commun., 2017, 53, 4585; (c)
P. Xiao, J. Rong, C. Ni, J. Guo, X. Li, D. Chen and J. Hu, Org. Lett., 2016, 18, 5912; (d) S. Lu, Y. Gong and D. Zhou, J. Org. Chem., 2015, 80, 9339; (e) J. J. Cao, T. H. Zhu, S. Y. Wang, Z. Y. Gu, X. Wang and S. J. Ji, Chem. Commun., 2014, 50, 6439; (f) L. Wang, W. X. Sha, Q. Dai, X. M. Feng, W. T. Wu, H. B. Peng, B. Chen and J. Cheng, Org. Lett., 2014, 16, 2088; (g) Z. J. Li, F. H. Fan, J. Yang and Z. Q. Liu, Org. Lett., 2014, 16, 3396; (h) W. X. Sha, J. T. Yu, Y. Jiang, H. T. Yang and J. Cheng, Chem. Commun., 2014, 50, 9179; (i) J. J. Cao, X. Wang, S. Y. Wang and S. J. Ji, Chem. Commun., 2014, 50, 12892; (j) L. J. Gu, C. Jin, J. Y. Liu, H. Y. Ding and B. M. Fan, Chem. Commun., 2014, 50, 4643; (k) Z. H. Xia, J. B. Huang, Y. M. He, J. J. Zhao, J. Lei and Q. Zhu, Org. Lett., 2014, 16, 2546; (l) H. Jiang, Y. Z. Cheng, R. Z. Wang, M. M. Zheng, Y. Zhang and S. Y. Yu, Angew. Chem., Int. Ed., 2013, 52, 13289; $(m)$ M. Tobisu, K. Koh, T. Furukawa and N. Chatani, Angew. Chem., Int. Ed., 2012, 51, 11363. for recent reviews see: $(n)$ B. Song and B. Xu, Chem. Soc. Rev., 2017, 46, 1103; (o) J. Lei, J. Huang and Q. Zhu, Org. Biomol. Chem., 2016, 14, 2593.

11 D. Leifert, C. G. Daniliuc and A. Studer, Org. Lett., 2013, 15, 6286.

12 J. Liu, C. Fan, H. Yin, C. Qin, G. Zhang, X. Zhang, H. Yi and A. Lei, Chem. Commun., 2014, 50, 2145.

13 Z. Nie, Q. Ding and Y. Peng, Tetrahedron, 2016, 72, 8350. 